\title{
Effects of Nursing Program As A life Review on Life Satisfaction And Happiness Among Elderly People
}

\author{
Abdel-Hady El-Gilany ${ }^{1}$ and Raefa Refaat Alam ${ }^{2}$ \\ ${ }^{1}$ Professor Of Public Health, Faculty Of Medicine, Mansoura University, Egypt \\ ${ }^{2}$ Lecturer Of Gerontological Nursing, Faculty Of Nursing, Mansoura University, Egypt
}

\begin{abstract}
:
Background: Life review can be an effective intervention in increasing the positive emotions, happiness and life satisfaction among elderly, which in turn will improve their life significantly. This study aims to determine the effects of nursing program as a life review on life satisfaction and happiness among elderly people.

Design: A quasi experimental study. Settings: Two elderly clubs namely; Elsaada and El-Amal in Mansoura, Egypt.

Subjects and Method: subjects included 74 elderly, Data collected are: socio-demographics, Subjective Happiness, and Satisfaction with Life Scales. Nursing program as (a life review) was implemented and the two scales were re-measured immediately and two months after intervention.

Results: There is an improvement of the overall median life satisfaction score in the immediate post-intervention and two months after intervention. These improvements are statistical significant with $P=0.001$. Also, the overall median happiness score improved from 14 up to 19.5 and 20 in the immediate and two-months postintervention; respectively. These improvements are statistical significant with $P=0.001$.This pattern of improvement persists after stratification of all the sociodemographic variables studied and with the presence or absence of chronic diseases.
\end{abstract}

Conclusion: Implementation of a Life review intervention improved the life satisfaction and sense of happiness among elderly immediately and post 8 weeks of intervention.

Keywords: Elderly people, Life satisfaction, Happiness, and Life review.

\section{Introduction}

Growth in the number of older persons is a global phenomenon. In Egypt the aged 60 years and more was $7.9 \%$ in 2015 and is expected to reach $9.9 \%$ of the population in $2030^{(1)}$.Therefore, aging is an important issue to address in an effort to help the elderly live as healthy individuals and to enhance their sense of happiness and life satisfaction ${ }^{(2)}$.

Life satisfaction is a broad term that can be interpreted in many different ways. For the older population it is a measure of happiness, integrity, and a sense of comfort about how once has lived one's life. It is characterized by a sense of purpose, personal growth, and self-acceptance ${ }^{(3,4)}$.Elders who are aging successfully continue to grow and to learn as they use past experience to cope with the present and set goals for the future ${ }^{(5}$, 6). The pursuit of happiness is an important goal for all human generations and is the most central human stimuli ${ }^{(7,8)}$. Happiness may be a psychological concept with many definitions and dimensions ${ }^{(9)}$. It is the degree to which individual decide their life quality. It is a positive emotion, associated with life satisfaction and absence of negative feelings. It also is an important criterion for psychological wellbeing ${ }^{(10)}$. It has been shown that happiness can lead to a favorable attitude towards life, a positive self-concept, higher levels of vitality and mental health; proper affect, and higher levels of social and physical functioning ${ }^{\mathbf{1 1 1}, \mathbf{1 2})}$.

Life reviews ${ }^{(13)}$ are among nursing interventions that have been used to improve self-esteem, socialization, life satisfaction and happiness in elderly person ${ }^{(14)}$. Life review or reminiscence therapy is an alternative to the traditional method of psychotherapy with older adults. Life review is based on reviewing life events, feelings and previous thoughts, in order to facilitate a sense of joy, enhance the standard of life, or adapt to current situations ${ }^{(14)}$. In life review, elderly reviews his/her life focusing on the Erickson's life-span developmental theory ${ }^{\left({ }^{(5)}\right.}$. Life review helps the elderly to restore life events and place them in a new mental structure to expand their understanding of the life meaning ${ }^{(16)}$.To the best authors' knowledge there are no studies on the effect of life review intervention on the satisfaction of life and happiness of elderly. This study aims to measure the effects of nursing program as a life review on life satisfaction and happiness among elderly people in Mansoura, Egypt.

Research Hypotheses: life satisfaction and happiness among elderly people may be improved after implementation of nursing program as a life review. 


\section{Population and Method}

This quasi-experimental research (pre-post intervention)was carried out in two elderly clubs namely; Elsaada and El-Amal elderly clubs, over a period of 6 months beginning at November 2016 till the end April 2017.The study subjects included a convenience sample of 74 elderly aged 60 years and above, able to communicate and accept to participate in the study.

\section{The following data was collected during an interview:}

1-Socio-demographic data such as age, sex, level of education, marital status, living condition, occupation before retirement and income as well as self-reported of chronic diseases.

2-The Subjective Happiness Scale (SHS) is a four-item scale designed to measure subjective happiness. Every item was completed by choosing one from all the seven options which ended a given sentence fragment. Every question had different options. The items from the subjective Happiness Scale were summed in order to form a complete score. The total points possible were twenty eight. A score of 28 , would indicate high levels of happiness (Lyubomirsky and Lepper, 1999) ${ }^{(17)}$.

3-The Satisfaction with Life Scale (SWLS) is a short five-item instrument designed to measure global cognitive judgments of satisfaction with one's life. The queries were answered according to a seven- item scale of Likert-type, starting from one (Strongly Disagree) to seven (Strongly Agree). Completion usually needs about one minute of the subjects' time. The items from the SWLS were summed in order to make a total score. The total points possible were thirty five. A score of thirty five would indicate high levels of satisfaction with life (Diener et al, 1985) ${ }^{(18)}$. Subjects indicate how much they agree or disagree with each of the five items using a seven-point scale that ranges from seven (strongly agree) to one (strongly disagrees.)

Though scoring should be kept continuous (sum up scores on every item), here are some cutoffs to be used as benchmarks:31 - 35 extremely satisfied; 26 - 30 satisfied; 21 - 25 slightly satisfied; 20 Neutral; 15 - 19 slightly dissatisfied; 10 - 14 dissatisfied and 5 - 9 extremely dissatisfied.

The Subjective Happiness and Satisfaction with Life Scales were translated into Arabic and tested for content validity by a jury of seven experts then they were tested for reliability by test-retest method throughout the pilot study. The reliability was assured by means of Cronbach's coefficient alpha. Subjective Happiness Scale has a reliability of 0.89 and Satisfaction with Life Scale 0.87. A pilot study was carried out on 10 elderly not included in the full-scale study to evaluate the ambiguity, clarity and applicability of the tools. Consequently, the necessary modifications were done.

Intervention: A Narrative Life Review script was adapted from Hospice of urban center. It includes twenty-nine queries concerning life experience from the time of babyhood to that of late adulthood. An example from the seventeen life -review intervention is, "Tell me about your greatest struggles as an adult that you had to overcome" (Hospice of Cincinnati, 2015) ${ }^{(19)}$.The queries were created with the purpose of celebrating the participant's life and cultivating a meaningful conversation between the participant and the researcher. Nursing program as (a life review) was translated into Arabic by researchers.

The intervention was implemented in a safe environment for participants in sizeable area with a quiet, warm, and comfortable atmosphere. Being able to sit in a circle allowed participants to have eye contact with each other, to hear what each person said, and to join the conversation whenever they wanted. Private photographs of the elderly were used to help those elderly to remember the past significant events, also sweets and gifts were offered during the celebration of Mother's Day in order to encourage socialization. Before beginning the first session, the researchers introduced themselves to the elderly and established to create trust, relief fears, and gain cooperation. The researchers started every session with easy structured question concerning the content of every session, and encourage each elderly to share and talk. Each session included simple recollection of positive autobiographical events, with the goal of fostering positive emotions. The studied elderly were divided into small groups of four to seven and life review sessions were held for four sessions, once weekly for the period of 4 weeks. The intervention consisted of open discussions on various topics, such as childhood stage, adolescent stage, adulthood, and older adulthood. Techniques were also incorporated into the intervention, such as role-playing and open discussion. Evaluation of the program was done immediately and two months after its implementation ${ }^{(2,8,20,21)}$.

\section{The four intervention sessions included:-}

Childhood stage: - The elderly were asked (What do you mostly confine in mind relating to your parents? What does one keep in mind mostly regarding his/ her parents? , what's your favorite childhood memory?, Who did you spend most of your time with as a child?, and Who had the most significant influence on you as a child?

Adolescent stage: The elderly talked regarding formal experiences (spiritual/secular/ education/achievements/awards), succor, and first love and greatest lessons at this age. 
Adulthood stage: The elderly talked regarding career selections, experiences, and any awards she/he received, travels, service, highest grade she/he completed, any struggles as an adult she/he had overcome and kids.

Older adulthood Stage: The elderly talked about grandchildren, great-grandchildren, career experiences, achievements, awards, health challenges and outcomes, greatest accomplishment in life and happiest time of life.

Ethical Considerations; All the elderly participants verbal consent was obtained before participation and was assured of the confidentiality of their personal information and privacy. Also, they had the right to withdraw from the study at any time.

Statistical analysis; Data was analyzed using SPSS version 16. The scores of satisfaction with life and happiness were tested for normality distribution by Shapiro's test and found to be non-parametric in distribution. Friedman's test was used for comparing scores of the pre-, immediate and two-months after interventions. Wilcoxon test was used for paired comparison of the pre and post intervention scores. $\mathrm{P} \leq 0.05$ was considered statistically significant.

\section{Results}

Age ranged from 60 to 77 with a mean of $67.0 \pm 4.37$ years and a median of 67 years. In preintervention $44.6 \%, 9.5 \%, 36.5 \%$ and $9.5 \%$ of elderly were slightly satisfied, neutral, slightly dissatisfied and dissatisfied; respectively. These changed into $55.4 \%, 35.1 \%$ and $9.5 \%$ were extremely satisfied, satisfied and slightly satisfied; respectively in the immediate post-intervention. However, these were changed into $27.0 \%$, $35.1 \%$ and $37.8 \%$ at two months post-intervention; respectively (data not shown in tables).

Table 1 shows that the pre-intervention overall median life satisfaction score improved from 20 up to 31 in the immediate post-intervention, however it decreased slightly to 28 two-months after intervention. These improvements are statistical significant with $\mathrm{P} \leq 0.001$. This pattern of improvement persists after stratification of all the sociodemographic variables studied and with the presence or absence of chronic diseases. Table 2 shows that the pre-intervention overall median happiness score improved from 14 up to 19.5 and 20 in the immediate and two-months post-intervention; respectively. These improvements are statistical significant with $\mathrm{P} \leq 0.001$.This pattern of improvement persists after stratification of all the sociodemographic variables studied and with the presence or absence of chronic diseases 
Table 1: Life satisfaction of elderly people before and post intervention and its variations with different variables.

\begin{tabular}{|c|c|c|c|c|c|}
\hline & Total & Pre-intervention & $\begin{array}{l}\text { Immediate post- } \\
\text { intervention }\end{array}$ & $\begin{array}{l}2 \text { months post- } \\
\text { intervention }\end{array}$ & $\begin{array}{l}\text { Significance } \\
\text { (Friedman's test) }\end{array}$ \\
\hline & & $\begin{array}{l}\text { Median (min- } \\
\max \text { ) }\end{array}$ & $\begin{array}{c}\text { Median } \\
(\min -\max )\end{array}$ & $\begin{array}{l}\text { Median } \\
(\min -\max )\end{array}$ & \\
\hline Overall & 74 & $20(14-25)^{\mathrm{A}, \mathrm{B}}$ & $31(23-35)^{\mathrm{A}, \mathrm{C}}$ & $28(21-32)^{\mathrm{B}, \mathrm{C}}$ & $\chi^{2}=116.1, \mathrm{P} \leq 0.001$ \\
\hline $\begin{aligned} \text { Age: } & 60- \\
& 65- \\
& 70 \& \text { more }\end{aligned}$ & $\begin{array}{l}25 \\
27 \\
22\end{array}$ & $\begin{array}{l}23(14-25)^{\mathrm{A}, \mathrm{B}} \\
19(14-25)^{\mathrm{A}, \mathrm{B}} \\
17(14-25)^{\mathrm{A}, \mathrm{B}}\end{array}$ & $\begin{array}{c}30(25-34)^{\mathrm{A}} \\
30(23-35)^{\mathrm{A}, \mathrm{C}} \\
32(28-35)^{\mathrm{A}, \mathrm{C}}\end{array}$ & $\begin{array}{c}30(22-32)^{\mathrm{B}} \\
26(21-31)^{\mathrm{B}, \mathrm{C}} \\
24(23-32)^{\mathrm{B}, \mathrm{C}}\end{array}$ & $\begin{array}{l}\chi^{2}=38.7, \mathrm{P} \leq 0.001 \\
\chi^{2}=40.9, \mathrm{P} \leq 0.001 \\
\chi^{2}=42.1, \mathrm{P} \leq 0.001\end{array}$ \\
\hline $\begin{aligned} \text { Sex: } & \text { Male } \\
& \text { Female }\end{aligned}$ & $\begin{array}{l}29 \\
45\end{array}$ & $\begin{array}{l}18(14-25)^{\mathrm{A}, \mathrm{B}} \\
21(14-25)^{\mathrm{A}, \mathrm{B}}\end{array}$ & $\begin{array}{l}31(25-35)^{\mathrm{A}, \mathrm{C}} \\
31(23-35)^{\mathrm{A}, \mathrm{C}}\end{array}$ & $\begin{array}{l}25(23-32)^{\mathrm{B}, \mathrm{C}} \\
27(21-32)^{\mathrm{B}, \mathrm{C}}\end{array}$ & $\begin{array}{l}\chi^{2}=49.2, \mathrm{P} \leq 0.001 \\
\chi^{2}=68.5, \mathrm{P} \leq 0.001\end{array}$ \\
\hline $\begin{array}{l}\text { Elderly club: } \\
\text { El-Amel } \\
\text { El-Saada }\end{array}$ & $\begin{array}{l}34 \\
40\end{array}$ & $\begin{array}{l}21(14-25)^{\mathrm{A}, \mathrm{B}} \\
19(14-25)^{\mathrm{A}, \mathrm{B}}\end{array}$ & $\begin{array}{l}30(25-35)^{\mathrm{A}, \mathrm{C}} \\
31(23-35)^{\mathrm{A}, \mathrm{C}}\end{array}$ & $\begin{array}{l}26(24-32)^{\mathrm{B}, \mathrm{C}} \\
26(21-32)^{\mathrm{B}, \mathrm{C}}\end{array}$ & $\begin{array}{l}\chi^{2}=49.9, \mathrm{P} \leq 0.001 \\
\chi^{2}=67.9, \mathrm{P} \leq 0.001\end{array}$ \\
\hline $\begin{array}{l}\text { Marital status: } \\
\text { Married } \\
\text { Others\# }\end{array}$ & $\begin{array}{l}45 \\
29\end{array}$ & $\begin{array}{l}20(14-25)^{\mathrm{A}, \mathrm{B}} \\
19(14-25)^{\mathrm{A}, \mathrm{B}}\end{array}$ & $\begin{array}{l}31(23-35)^{\mathrm{A}, \mathrm{C}} \\
31(25-35)^{\mathrm{A}, \mathrm{C}}\end{array}$ & $\begin{array}{l}26(21-32)^{\mathrm{B}, \mathrm{C}} \\
26(23-32)^{\mathrm{B}, \mathrm{C}}\end{array}$ & $\begin{array}{l}\chi^{2}=71.5, \mathrm{P} \leq 0.001 \\
\chi^{2}=44.6, \mathrm{P} \leq 0.001\end{array}$ \\
\hline $\begin{array}{l}\text { Education: } \\
\text { <secondary } \\
\text { Secondary } \\
\text { >secondary }\end{array}$ & $\begin{array}{l}12 \\
36 \\
26\end{array}$ & $\begin{array}{c}18.5(14-20)^{\mathrm{A}, \mathrm{B}} \\
21(14-25)^{\mathrm{A}, \mathrm{B}} \\
18.5(14-25)^{\mathrm{A}, \mathrm{B}} \\
\end{array}$ & $\begin{array}{l}32(28-35)^{\mathrm{A}, \mathrm{C}} \\
30(25-35)^{\mathrm{A}, \mathrm{C}} \\
31(23-35)^{\mathrm{A}, \mathrm{C}}\end{array}$ & $\begin{array}{l}25(22-27)^{\mathrm{B}, \mathrm{C}} \\
27(23-31)^{\mathrm{B}, \mathrm{C}} \\
26(21-32)^{\mathrm{B}, \mathrm{C}}\end{array}$ & $\begin{array}{l}\chi^{2}=24.0, \mathrm{P} \leq 0.001 \\
\chi^{2}=529, \mathrm{P} \leq 0.001 \\
\chi^{2}=42.6, \mathrm{P} \leq 0.001\end{array}$ \\
\hline $\begin{array}{l}\text { Income: } \\
\text { Enough } \\
\text { Not enough } \\
\text { Enough and save }\end{array}$ & $\begin{array}{l}44 \\
13 \\
17 \\
\end{array}$ & $\begin{array}{l}21(14-25)^{\mathrm{A}, \mathrm{B}} \\
17(14-20)^{\mathrm{A}, \mathrm{B}} \\
18(14-25)^{\mathrm{A}, \mathrm{B}}\end{array}$ & $\begin{array}{l}30(23-35)^{\mathrm{A}, \mathrm{C}} \\
32(28-35)^{\mathrm{A}, \mathrm{C}} \\
31(25-35)^{\mathrm{A}, \mathrm{C}}\end{array}$ & $\begin{array}{c}28.5(21-32)^{\mathrm{B}, \mathrm{C}} \\
24(22-27)^{\mathrm{B}, \mathrm{C}} \\
24(23-32)^{\mathrm{B}, \mathrm{C}} \\
\end{array}$ & $\begin{array}{l}\chi^{2}=67.0, \mathrm{P} \leq 0.001 \\
\chi^{2}=26.0, \mathrm{P} \leq 0.001 \\
\chi^{2}=27.7, \mathrm{P} \leq 0.001\end{array}$ \\
\hline $\begin{array}{l}\text { Residence: } \\
\text { Rural } \\
\text { Urban }\end{array}$ & $\begin{array}{l}23 \\
51\end{array}$ & $\begin{array}{l}20(14-25)^{\mathrm{A}, \mathrm{B}} \\
20(14-25)^{\mathrm{A}, \mathrm{B}}\end{array}$ & $\begin{array}{l}30(23-35)^{\mathrm{A}, \mathrm{C}} \\
31(25-35)^{\mathrm{A}, \mathrm{C}}\end{array}$ & $\begin{array}{l}26(21-31)^{\mathrm{B}, \mathrm{C}} \\
26(22-32)^{\mathrm{B}, \mathrm{C}}\end{array}$ & $\begin{array}{l}\chi^{2}=34.5, \mathrm{P} \leq 0.001 \\
\chi^{2}=81.6, \mathrm{P} \leq 0.001\end{array}$ \\
\hline $\begin{array}{l}\text { Leisure activities: } \\
\text { Yes } \\
\text { No }\end{array}$ & $\begin{array}{l}46 \\
28\end{array}$ & $\begin{array}{c}21(15-25)^{\mathrm{A}, \mathrm{B}} \\
17.5(14-21)^{\mathrm{A}, \mathrm{B}}\end{array}$ & $\begin{array}{l}29(23-35)^{\mathrm{A}, \mathrm{C}} \\
32(28-35)^{\mathrm{A}, \mathrm{C}}\end{array}$ & $\begin{array}{l}29(21-32)^{\mathrm{B}, \mathrm{C}} \\
25(23-28)^{\mathrm{B}, \mathrm{C}}\end{array}$ & $\begin{array}{l}\chi^{2}=68.6, \mathrm{P} \leq 0.001 \\
\chi^{2}=56.0, \mathrm{P} \leq 0.001\end{array}$ \\
\hline $\begin{array}{l}\text { Living } \\
\text { arrangement } \\
\text { Alone/elderly } \\
\text { home } \\
\text { With wife/husband } \\
\text { With family }\end{array}$ & $\begin{array}{l}11 \\
20 \\
43\end{array}$ & $\begin{array}{l}19(14-24)^{\mathrm{A}, \mathrm{B}} \\
17(14-25)^{\mathrm{A}, \mathrm{B}} \\
21(14-25)^{\mathrm{A}, \mathrm{B}}\end{array}$ & $\begin{array}{l}32(28-35)^{\mathrm{A}, \mathrm{C}} \\
31(23-35)^{\mathrm{A}, \mathrm{C}} \\
30(25-35)^{\mathrm{A}, \mathrm{C}}\end{array}$ & $\begin{array}{l}25(24-27)^{\mathrm{B}, \mathrm{C}} \\
25(21-31)^{\mathrm{B}, \mathrm{C}} \\
28(22-32)^{\mathrm{B}, \mathrm{C}}\end{array}$ & $\begin{array}{l}\chi^{2}=22.0, \mathrm{P} \leq 0.001 \\
\chi^{2}=36.1, \mathrm{P} \leq 0.001 \\
\chi^{2}=63.8, \mathrm{P} \leq 0.001\end{array}$ \\
\hline $\begin{array}{l}\text { Chronic diseases\#\# } \\
\text { Yes } \\
\text { No }\end{array}$ & $\begin{array}{l}51 \\
23\end{array}$ & $\begin{array}{l}20(14-25)^{\mathrm{A}, \mathrm{B}} \\
21(14-25)^{\mathrm{A}, \mathrm{B}}\end{array}$ & $\begin{array}{l}31(23-35)^{\mathrm{A}, \mathrm{C}} \\
30(25-35)^{\mathrm{A}, \mathrm{C}}\end{array}$ & $\begin{array}{l}26(21-32)^{\mathrm{B}, \mathrm{C}} \\
27(24-32)^{\mathrm{B}, \mathrm{C}}\end{array}$ & $\begin{array}{l}\chi^{2}=81.6, \mathrm{P} \leq 0.001 \\
\chi^{2}=34.5, \mathrm{P} \leq 0.001\end{array}$ \\
\hline
\end{tabular}

\#Single (3), divorced (14) and widow (12)

\#\#e.g. Hypertension, coronary heart disease, bronchial asthma, COPD, Senile prostate, etc.

A,B,C significant difference between the corresponding values by Wilcoxon's test forpaired comparison 
Table 2: Happiness of elderly people before and post intervention and its variations with different variables.

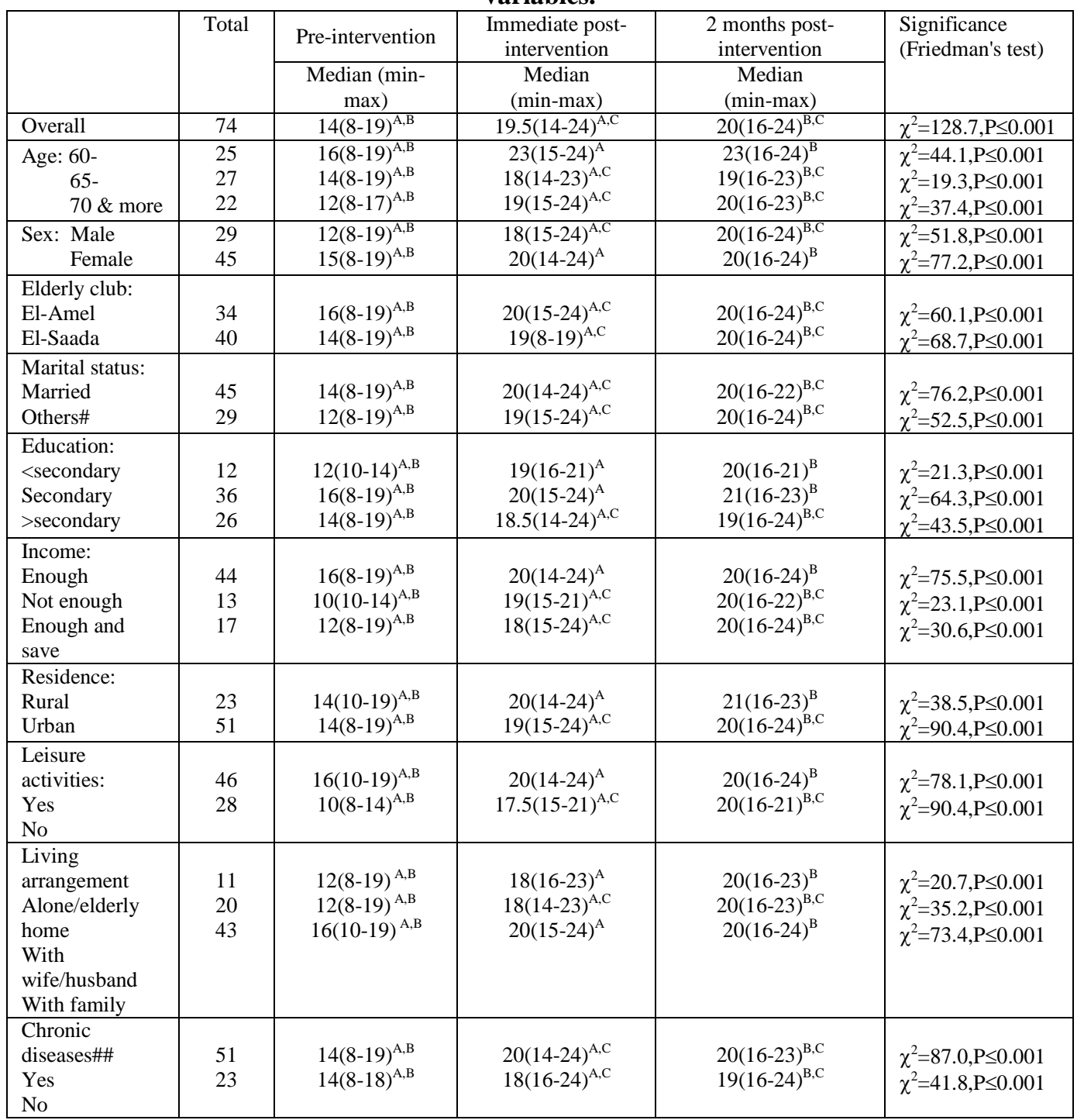

\#Single (3), divorced (14) and widow (12)

\#\#е.g. Hypertension, coronary heart disease, bronchial asthma, COPD, Senile prostate, etc.

A,B,C significant difference between the corresponding values by Wilcoxon test for paired comparison

\section{Discussion}

In this study the effects of the life review program were assessed within two target areas, life satisfaction and happiness. The contents of the life review provided opportunities for the elderly to interact with each other, providing them a greater opportunity to explore the value of their lives and activities. Once possessing direction and purpose, their life satisfaction may improve. The present study results revealed that the pre-intervention overall median life satisfaction score improved from 20 up to 31 in the immediate postintervention, however it decreased slightly to 28 two-months after intervention, Moreover the women more satisfied than men, this can be explained by the fact that the elderly exploit any opportunity allows them to interact with others and express feelings; also the supportive atmosphere of the group created a sense of togetherness, of being accepted and being a valued group member. These results are in agreement with Davis (2004) $)^{22}$ in France and Height et al $\mathbf{( 2 0 0 0 )}^{23}$ in USA; They found that the life satisfaction was statistically increased from the pre-test to the post-test and at the 1-month follow-up, indicating that the life review Program preserved and maintained the internal and external structures of the elderly by reviewing past experiences in order to counter present difficulties. Another study done in California found that the participants' life 
satisfaction scores improved significantly from the pretest to the posttest. The posttest was given directly after the final session (Mathieu, 2008) ${ }^{24}$.

A previous study in Egypt revealed a statistically significant decreased in depression scores compared before, immediately and three months after the implementation of reminiscence group therapy ${ }^{21}$. Moral et al $\mathbf{( 2 0 1 3 )}^{\mathbf{2 5}}$ revealed that the treatment group's scores on depressive symptomatology, self-esteem, life satisfaction, and psychological well-being all improved, while the control group's scores on the study's variables stayed the same or even decreased. Chiang et al. $(\mathbf{2 0 1 0})^{26}$ proposed that reminiscence therapy is also effective at improving comprehension skills and fomenting life satisfaction. That was confirmed by the significant improvement in score observed.

In addition, these results are consistent with those of Davis (2004) ${ }^{22}$, who reported that satisfaction level increased in groups who received therapy, compared to the control group. A study done by O'Rourke et al, (2011) ${ }^{20}$ in Span found a life review program in institutionalized people over 65 elucidated significant differences that reflect improvement on the study's variables. We observed that the treatment group's scores on depressive symptomatology, self-esteem, life satisfaction, and psychological well-being all improved, while the control group's scores on the study's variables stayed the same or even decreased.A Study done in Malaysia by Dahlan et al (2010) ${ }^{9}$ reported that the level of life satisfaction is equivalent to the norms and there is no statistical significant Difference between the levels with the demographic variables.

In the contrary a previous qualitative study in USA which revealed that the life review intervention failed to have an effect on participants' levels of life satisfaction and subjective happiness in most of the participants. Moreover, Arkoff et al, (2004) $)^{27}$, reported that retrospective-proactive life review had no significant effect on happiness of older women. Also, in a study on the effects of group life review, Chao et al, (2006) ${ }^{14}$ reported that this technique improved the old people's self-esteem but had no significant effect on life satisfaction.

The present study reported that the pre-intervention overall median happiness score improved immediate and two-month post-intervention. These improvements are statistical significant. These results consistent with Yousefi et al, (2015) ${ }^{8}$ stated that the mean happiness scores of the intervention group in the four measurement times revealed a significant difference only after the third and sixth sessions $(\mathrm{P}=0.03)$. Several previous studies have also reported mixed results about the effects of life review on various aspects of mental health. In a quasi-experimental study, Bohlmeijer et al (2008) ${ }^{28}$ reported that integrative reminiscence significantly improved the overall meaning of life, sense of happiness and social relations of elderly participants. Another study done in Iran by Yousefi et al, (2014) ${ }^{29}$ found that the group discussion and life review are effective in increasing the elderly happiness scores. However, life review was a more effective intervention; therefore, it can be an inexpensive way to increase the vitality of the elderly with no side-effects. The same results reported by some former studies ${ }^{(30,31) \text {. }}$

The study results reported that there is a statistically significant difference between demographic characteristics of the elderly and increase in mean happiness and life satisfaction score before and after the intervention this is in agreement with Mathieu (2008) $)^{24}$ and Vaznoniene (2016) ${ }^{32}$ mentioned in their study, a significant differences were found between the study group in terms of socio- demographic characteristics and happiness and women are happier than men; the characteristics of wellbeing of economically active elderly population are better.

\section{Conclusions}

This study concluded that the implementation of a Life review intervention improved the life satisfaction and sense of happiness of the elderly immediately and post 8 week of intervention.

\section{Recommendations}

Based on the findings of this study, the following recommendations are suggested:

- In service training program to caregivers especially family members about life review intervention.

- Comedic videos can be used within the program.

- Each session should incorporate entertainment and education.

- Programs should meet regularly.

Study Limitations: This study involved a convenience sample of elderly attending to elderly clubs the results of which may not reflect the general population of the elderly living in the other setting. Another limitation is short duration of follow-up to two months only. We therefore suggest performing a long-term follow- up study in the future that can examine the longitudinal effects of the life review program. 


\section{Conflicts of Interests: None}

\section{References}

[1]. United Nations, Department of Economic and Social Affairs, Population Division (2015). World Population Ageing 2015 Highlights (ST/ESA/SER.A/368).

[2]. Chiang K, Lu R, Chu H, et al. Evaluation of the effect of a life review group program on self-esteem and life satisfaction in the elderly. Int. J. Geriatr. Psychiatry 2008; 23: 7-10.

[3]. Meggiolaro S and Ongaro F. Life satisfaction among the elderly in Italy in a gender approach. Working Paper Series, N.6, April 2013.

[4]. Porter C, Alarcon D, and Padura A. Dwelling conditions and life satisfaction of older people through residential satisfaction. J of Environmental Psychology49 (2017):1-7.

[5]. Chen F, Yang M, Gao W, Liu Y, and Gieter S. Impact of satisfaction with psychological reward and pay on Chinese nurses work attitudes. Applied Nursing Research 28(2015) e29-e34.

[6]. White M. "Effects of Life Review on Happiness and Life Satisfaction in Older Adults" (2015).Masters Theses \& Specialist Projects. Paper 1519.http://digitalcommons.wku.edu/theses/1519. A Thesis Presented to The Faculty of the Department of Psychology, Western Kentucky University, and Bowling Green, KY.

[7]. Steptoe A, Wardle J, Marmot M. Positive affect and health-related neuroendocrine, cardiovascular, and inflammatory processes. Proc Natl Acad Sci U S A. 2005; 102(18):6508-12.

[8]. Yousefi Z, Sharifi K, Tagharrobi Z, and Akbari H. The Effect of Narrative Reminiscence on Happiness of Elderly Women. Iran Red Crescent Med J. 2015 November; 17(11): e19612.

[9]. Dahlan K, Nicol M and Maciver D. Elements of life satisfaction amongst elderly people living in institutions in Malaysia: a mixed methodology approach. HKJOT 2010; 20(2):71-79.

[10]. Kashdan TB, Biswas-Diener R, King LA. Reconsidering happiness: the costs of distinguishing between hedonics and eudaimonia. J Posit Psychol. 2008; 3(4):219-33.

[11]. Lyubomirsky S, Sheldon KM, Schkade D. Pursuing happiness: The architecture of sustainable change. Rev General Psych. 2005; 9(2):111-31.

[12]. Diener E. The Science of Well-Being. Netherlands: Springer; 2009

[13]. Hsieh HF, Wang JJ. Effect of reminiscence therapy on depression in older adults: a systematic review. Int $\mathbf{J}$ Nurs Stud. 2003;40(4):335-45.

[14]. Chao SY, Liu HY, Wu CY, Jin SF, Chu TL, Huang TS, et al. The effects of group reminiscence therapy on depression, self-esteem, and life satisfaction of elderly nursing home residents. J Nurs Res. 2006; 14(1):36-45.

[15]. Chen TJ, Li HJ, Li J. The effects of reminiscence therapy on depressive symptoms of Chinese elderly: study protocol of a randomized controlled trial. BMC Psychiatry. 2012; 12:189.

[16]. Ando M, Morita T. Efficacy of the structured life review and the short-term life review on the spiritual well-being of terminally ill cancer patients. Health. 2010; 02(04):342-6.

[17]. Lyubomirsky, S. \&Lepper, H. S.A measure of subjective happiness: Preliminary reliability and construct validation. Social Indicators Research1999; 46, 137-155.

[18]. Diener, E., Emmons, R. A., Larsen, R. J., \& Griffin, S. The Satisfaction with Life Scale. Journal of Personality Assessment1985, 49, 71-75.

[19]. Hospice of Cincinnati. Information you may want to include in a life review. $2015 . \quad$ Retrieved from http://www.hospiceofcincinnati.org/life_review_info.shtml.

[20]. O'Rourke, N., Cappeliez, P., \& Claxton, A. Functions of reminiscence and the psychological well-being of young-old and older adults over time. Aging \& Mental Health2011; 15, 272-281.

[21]. Saleh N and Salama E. Effect of Group Reminiscence Therapy on Depression among institutionalized elderly in Dakahlia Governorate - Egypt. IOSR Journal of Nursing and Health Science (IOSR-JNHS) e-ISSN: 2320-1959.p- ISSN: 2320-1940 Volume 5, Issue 5 Ver. II (Sep. - Oct. (2016), PP 19-26

[22]. Davis MC. Life review therapy as an intervention to manage depression and enhance life satisfaction in individuals with right hemisphere cerebral vascular accidents. Issues Ment Health Nurs . 2004; 25: 503-515.

[23]. Haight BK, Michel Y, Hendrix S.The extended effects of the life review in nursing home residents. Int J Aging Hum Dev,2000; 50: 151-168.

[24]. Mathieu S. Happiness and Humor Group Promotes Life Satisfaction for Senior Center Participants. Activities, Adaptation \& Aging, Vol. 32(2) 2008

[25]. Moral J, Ruiz L, Rodríguez T and Galán A. Effects of a reminiscence program among institutionalized elderly adults.Psicothema 2013, Vol. 25, No. 3, 319-323

[26]. Chiang, K.J., Chu, H., Chang, H.J., Chung, M.H., Chen, C.H., Chiou, H.Y., \& Chou, K.R. The effects of reminiscence therapy on psychological well-being, depression, and loneliness among the institutionalized aged. International Journal of Geriatric Psychiatry, 2010; 25, 380-388.

[27]. Arkoff A, Meredith GM, Dubanoski JP. Gains in Well-Being Achieved Through Retrospective-Proactive Life Review By Independent Older Women. J Human Psych. 2004; 44(2):204-14.

[28]. Bohlmeijer ET, Westerhof GJ, Emmerik-de Jong M. The effects of integrative reminiscence on meaning in life: results of a quasiexperimental study. Aging Ment Health. 2008; 12(5):639-46.

[29]. Yousefi z, Sharifi k, Tagharrobi z and Akbari H. The effect of group reminiscence on happiness of the elderly. Evidence based care. 2014;4(3):33-36.

[30]. Tuntichaivanit C, Nanthamongkolchai S, Munsawaengsub C, Charupoonphol P. Life Happiness of the Elderly in Rayong Province. J. Public Health. 2013; 39(1):39-47. 8

[31]. Diener M. Frequently Asked Questions (FAQ's) About Subjective Well-Being (Happiness and Life Satisfaction): a Primer for Reporters and Newcomers. 2007; Available from: : http://www.Psych.uiuc.edu /ediener/faq.html

[32]. Vaznoniene G. Socio-demographic factors of elderly subjective wellbeing in lithuania. Jelgava, LLU ESAF, 21-22 April 2016, pp. $125-125$. 